\title{
QAIDAH FURU' FI AL-RIBA DAN IMPLEMENTASINYA
}

\author{
Doli Witro ${ }^{1}$, Mohamad Sar'an ${ }^{2}$, Deden Effendi ${ }^{3}$ \\ UIN Sunan Gunung Djati Bandung ${ }^{1,2,3}$ \\ doliwitro01@gmail.com¹,mohamad_saran@uinsgd.ac.id ${ }^{2}$, dedeneffendi@uinsgd.ac.id $^{3}$
}

\begin{abstract}
In the texts, namely the Al-Quran and hadith, many provisions are developed from the text itself, one of which is the rules of fikih. There are many discussions of fikih principles related to the muamalah contract and discussions outside the contract, such as usury. There are many verses of the Al-Quran and hadiths that prohibit people from practicing usury so that usury is categorized as a grave sin and mujma' 'alaih. This paper briefly explains the rules of fikih about usury. This study aims to understand the community or what kind of debt is categorized as usury. This article uses a qualitative approach that is the library in nature. The data in this study come from books and journals related to the topics discussed, namely the kaidahfuru' fi al-riba. The data analysis technique used was data reduction, data presentation, and conclusion drawing. The results of the analysis show that muamalah transactions in any form are not prohibited, but muamalah transactions that are prohibited are muamalah transactions that contain elements of usury.
\end{abstract}

Keywords:Principle of Fikih, Usury, Usury Law

\section{PENDAHULUAN}

Dalam Islam permasalahan mengenai ekonomi mendapat perhatian yang cukup besar. Hal ini terkonfirmasi dengan banyaknya nash yang berbicara mengenai hukum, etika, bahkan upaya preventif yang berkaitan dengan hal-hal yang dipatuhi dalam Islam ketika berbisnis (Hammam, 2017, p. 50). Dalam nash yaitu Al-Quran dan hadis, ada banyak sekali ketentuanketentuan yang dikembangkan berangkat dari nash itu sendiri, salah satunya adalah kaidah fikih(Witro, 2021, p. 2). Pembahasan tentang kaidah fikih terdapat banyak sekali yang berkaitan dengan akad muamalah, maupun pembahasan di luar akad seperti riba.

Allah sebagai pencipta alam raya ini menitipkan manusia rezeki dan kemampuan untuk mengolah dan memanfaatkan dengan cara yang bersih dari perbuatan yang mengandung riba atau dengan cara yang dihalalkan oleh Allah s.w.t. (Chair, 2014, p. 98). Ada banyak ayat Al-Quran dan hadis yang melarang manusia mempraktekkan riba, sehingga riba dikategorikan sebagai dosa besar dan mujma' 'alaib. Kendati demikian, praktek riba banyak yang menilai sering terjadi di dunia perbankan, khususnya perbankan konvensional. Hal utama yang menjadikan dunia perbankan berkonotasi riba adalah karena bunga yang dihasilkannya. Paradigma ini didukung 
oleh banyak orang mengira riba memiliki karakteristik yang sama dengan bunga bank, atau sebaliknya(Bakar, 2018, p. 3).

Tulisan ini menjelaskan secara singkat kaidah fikih tentang riba. Selain itu, tulisan juga menjelaskan implementasi kaidah riba pada kasus riba seperti pinjam-meminjam yang dilakukan masyarakat maupun tentang praktek bunga bank oleh sebagian masyarakat. Kajian ini bertujuan untuk memberikan pemahaman kepada masyarakat pinjam-meminjam atau utang-piutang seperti apa yang dikategorikan sebagai riba.

\section{TINJAUAN UMUM TENTANG RIBA DALAM MUAMALAH}

Riba menurut kacamata umat Islam adalah haram. Sebagian besar di antaranya dapat memahami definisi hingga detailnya. Namun, sebagian di antaranya tidak dapat mewujudkan pemahaman mereka dalam praktiknya. Kata riba secara kebahasaan bermakna riyadah, yang mana memiliki arti "bertambah" (Nurhadi, 2019, pp. 78-79). Sedangkan makna riba secara istilah yaitu pengambilan nilai tambah terhadap harta pokok dan atau modal dengan cara-cara yang tidak dibenarkan syariat (Fahriana \& Muslimin, 2020, pp. 119-120). Praktek riba dengan mengambil tambahan sering terjadi pada utang-piutang, baik yang berawal dari transaksi jual beli atau pinjam meminjam yang pembayaran ditangguhkan di masa mendatang dengan tambahan yang telah ditentukan di awal (Busyro, 2009, pp. 2-3).

Para ulama sepakat pinjaman atau utang piutang dibolehkan dalam muamalah karena dalam pelaksanaan prakteknya dapat meringankan beban orang lain tanpa maksud mendapat imbalan apapun dari orang yang dibantu. Sebagai makhluk hidup, sudah kodratnya manusia memerlukan banyak banyak kebutuhan. Oleh karena itu dalam memenuhi kebutuhan ekonominya, manusia membutuhkan bantuan orang lain salah satunya dengan bermuamalah (Witro, 2019, pp. 34-35). Islam memberikan tuntunan kepada kedua belah pihak yang melakukan transaksi muamalah agar saling mendapat keuntungan sama lain, dan bukan hanya menguntungkan salah satu pihak saja sementara pihak yang lain dirugikan (Irawati \& Akramunnas, 2018, p. 110).

Utang piutang yang dikategorikan riba adalah apabila terdapat pihak yang dirugikan dengan sistem pinjaman berbunga yang dapat mengeksploitasi pihak yang berhutang (Marwini, 2017, p. 4). Para ulama telah sepakat menyatakan bahwa riba hukumnya dilarang dalam muamalah, hal ini berdasarkan yang dijelaskan dalam Al-Quran, hadis, dan ijma' para ulama. Para cendikiawan mengemukakan praktek riba menyebabkan orang yang kaya semakin kaya dan orang yang miskin semakin miskin, karena transaksi muamalah dengan sistem riba dapat menghambat aktivitas perekonomian masyarakat (Salam, 2016, p. 91). 
Doli Witro dkk. Qaidah Furu' Fi Al-Riba dan Implementasinya

Pengetahuan merupakan hal yang utama membuat manusia mempraktekkan riba karena perilaku manusia dipengaruhi oleh pengetahuan yang ia miliki. Perilaku merupakan aktivitas atau kegiatan individu makhluk hidup yang dilakukan secara terkait dan bersambung-sambung. Oleh karenanya semua makhluk hidup itu baik manusia, binatang, maupun memiliki perilaku yang tercermin dari aktivitasnya masing-masing dalam sehari-hari. Sidi Gazalba sebagaimana Irawati dan Akramunnas mengemukakan pengetahuan adalah hasil pekerjaan tahu atau apa yang diketahui seseorang. Pekerjaan tahu yaitu hasil dari mengerti, kenal, insaf, sadar, dan pandai. Pengetahuan itu merupakan semua isi pikiran yang dimiliki manusia yang diperoleh hasil pengamatan panca indera yang sebagian besar pengetahuan tersebut didapatkan dari telinga dan mata (Irawati \& Akramunnas, 2018, p. 112).

Berdasarkan hasil penelitian Mada Wijaya (2007) sebagaimana yang dikutip Irawati dan Akramunnas menunjukkan bahwa masyarakat yang tudak memiliki pengetahuan yang luas tentang riba, cenderung akan menganggap riba merupakan tambahan yang sangat tinggi sebagaimana yang dilakukan oleh para rentenir, sementara yang tambahan dengan jumlah yang sedikit bukan termasuk riba. Kebanyakan masyarakat tidak memahami bahwa setiap jual beli yang dilakukan di sekitar mereka mengandung riba atau tidak. Mereka hanya terfokus pada pinjaman di bank konvensional yang mengandung unsur riba. Oleh karena itulah masyarakat memiliki persepsi bahwa tidak ada hutan piutang yang mempunyai baik membayar dengan pribadi maupun dalam kegiatan kelompok (Irawati \& Akramunnas, 2018, pp. 111-112).

Sektor perekonomian saat ini tidak bisa terlepas dari bank yang menjadi lalu lintas keuangan. Bank sebagai pusat perputaran uang dan alat tukar serta pembayaran, akan memperoleh keuntungan dari perniagaan kredit yang ditawarkan. Bunga bank dari angsuran kredit menjadi masukan bersih yang didapat dari nasabah yang berhutang kepada bank, atau keuntungan yang diberikan pihak bank kepada nasabah yang menyimpan uang di bank dengan besaran keuntungan menyesuaikan dengan kebijakan bank tersebut (Salam, 2016, p. 78). Disadari bahwa bunga bank membantu perkembangan dan eksistensi bank di tengah dinamika perekonomian masyarakat. Namun, dalam praktiknya bunga bank tampak mengeksploitasi nasabahnya dengan sistem kredit disertai dengan persentase bunga, baik bunga modal maupun bunga jatuh tempo. Sehingga Dakhoir dan Tarantang sepakat bahwa bunga bank diasumsikan sebagai salah satu praktik riba (Dakhoir \& Tarantang, 2020, p. 1).

Merespon kontroversi bunga bank sebagai riba, Qadir berpendapat bahwa umat Islam dilarang mengambil riba apapun jenisnya dan tidak diperkenankan melibatkan diri dengan riba (Qadir, 2014, p. 81). Islam melarang riba dengan alasan untuk menghindari praktik ekonomi yang tidak adil dan zalim dalam masyarakat (Dakhoir \& Tarantang, 2020, p. 2). Salam mengutip dari 
Hatta yang berpendapat bahwa jika bunga bank tersebut dilarang, maka tidak diperkenankan pula masyarakat Islam mendirikan bank syariah. Hatta sepakat bahwa bunga bank adalah tindakan yang tidak terpuji, namun jika masyarakat menghendakinya maka hukumnya diperbolehkan. Pandangan demikian menunjukkan sikap Hatta yang mempertimbangkan hukum dari baik dan buruknya secara maslahah mursalah dan sadd adz-dzariab(Salam, 2016, p. 78). Pendapat kontroversial yang dikemukakan Muhammad Syahrur terkait bunga bank adalah halal atau boleh selama bunga tidak mencapai 100\% (Qadir, 2014, p. 85). Hal ini tentu akan meningkatkan laju perkembangan bank konvensional sekaligus menghambat eksistensi bank syari'ah yang berupaya menghindari bunga bank dan perselisihan hukum antar ulama.

\section{METODE PENELITIAN}

Artikel ini menggunakan pendekatan kualitatif yang bersifat pustaka. Data-data dalam penelitian ini berasal dari buku-buku dan jurnal-jurnal yang berkaitan dengan topik yang dibahas yaitu kaidah furu' fi al-riba. Data dalam artikel ini disajikan dengan deskriptif. Ketika menyajikan data, pertama-tama dijelaskan tentang teori tinjauan al-riba secara umum, kemudian hukumnya, dan selanjutnya kaidah-kaidah furu' tentang al-riba. Dalam menjelaskan kaidah-kaidah furu' al-riba didukung dengan deskripsi (singkat) untuk menjelaskan makna dan maksud kaidah-kaidah tersebut. Teknis analisis data yang digunakan yaitu reduksi data, penyajian data, penarikan kesimpulan (Miles \& Huberman, 1984, pp. 21-24).

\section{HASIL DAN PEMBAHASAN}

\section{Kaidah-Kaidah Furu' Fi Al-Riba dan Implementasinya}

\section{a. Kaidah kesatu}

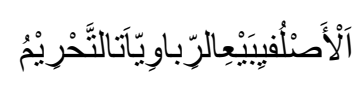

Artinya:

Hukum asal dalam jual beli benda ribawi adalah haram.

Kaidah tersebut maksudnya berkaitan dengan penegasan hukum asal riba adalah haram. Namun, kaidah tersebut terdapat pengecualian karena dibatasi oleh persyaratan tertentu, seperti adanya persyaratan sama kualitasnya (tamasul), kontan (bulul), dan diserahkan ketika akad (taqabud). Ketiga syarat tersebut ketika benda dipertukarkan adalah sejenis (ittibadul jinsi). Sedangkan ketika berbeda jenisnya, maka syaratnya hanya kontan dan serah terima. Kaidah tersebut secara eksplisit bersandar pada hadis Nabi yang melarang menukarkan emas dengan emas atau perak dengan perak, kecuali sama timbangannya (E. Hidayat, 2019, p. 304). Atau objek 
yang diperjualbelikan dapat diserahterimakan pada saat itu juga, seperti penukaran uang asing melalui ATM maka hukumnya boleh karena penukaran uang rupiah dengan Dollar harganya sesuai dengan kurs pada hari itu(Salim, 2017, p. 378).

\section{b. Kaidah kedua}

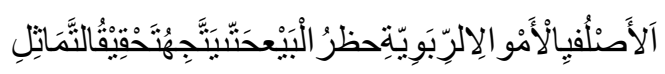

Artinya:

Hukum asal benda ribawi adalah dilarang melakukan tukar-menukar sehingga jelas adanya persamaan.

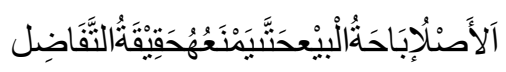

Artinya:

Hukum asal tukar menukar-menukar sesuatu diperbolehkan, sehingga terdapat bakikat kelebihan yang melarangnya.

Kaidah tersebut maksudnya berkaitan dengan larangan melakukan tukar-menukar benda ribawi kecuali adanya persamaan baik dalam jenis timbangan, maupun kualitasnya. Benda ribawi dimaksud emas, perak, gandum, jemawut, kurma, dan garam sebagaimana dijelaskan dalam hadis Nabi riwayat Muslim Abu Said al-Khudri. Secara umum benda ribawi tersebut terbagi ke dalam dua bagian, yakni emas dan perak dan makanan pokok serta makanan tambahan. Namun untuk konteks zaman sekarang, termasuk emas dan perak adalah mata uang seperti Rupiah, Dollar, dan lainnya; sedangkan makanan pokok selain disebutkan di atas adalah beras dan jagung yang disesuaikan dengan makanan pokok daerah masing-masing. Ditambah dengan makanan pelengkap seperti sayur-sayuran dan buah-buahan. Kaidah selanjutnya menerangkan diperbolehkan melakukan tukar-menukar benda ribawi sehingga terdapat kelebihan di dalamnya. Namun secara implisit maksud kaidah tersebut menegaskan larangan mempraktikkan riba, kecuali benda ribawi yang dipertukarkan itu adanya sama jenisnya, timbangannya, dan kualitasnya. Jika syarat tersebut terpenuhi, maka hal itu diperbolehkan (E. Hidayat, 2019, pp. 304-305). Contoh lain juga terdapat pada kebiasaan masyarakat Arab Jahiliah yang sering menukar benda sejenis, namun terdapat perbedaan pada salah satu pihak, baik itu timbangannya, jenisnya, maupun kualitasnya. Oleh karenanya hal ini dikategorikan riba fadhal, seperti menukar anggur kering dengan anggur basah, kurma kering dengan kurma basah, yang berlebih pada salah satu pihak yang bertransaksi. (Busyro, 2009, p. 3).

\section{c. Kaidah ketiga}

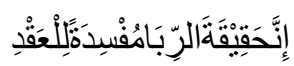

Artinya:

Sesunggubnya riba dapat merusak akad.

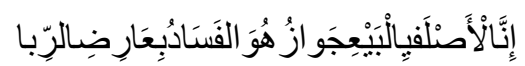


Artinya:

Hukum asal dalam jual beli adalah boleh dan menjadi fasad apabila terdapat.

$$
\text { مُفْسِدَاُالْغَرَرِ أَقَلْمِنَالَرِبَا }
$$

Artinya:

Kerusakan karena gharar lebih sedikit dibanding dengan riba.

Para ulama sepakat bahwa hukum jual beli adalah halal, atau boleh dilakukan selama tidak keluar dari ketentuan-ketentuan yang ditetapkan syari'at (Batubara, 2017, pp. 136-137). Salah satunya adalah sesuatu yang dapat merusak akad. Kaidah tersebut maksudnya berkaitan dengan bahaya riba bagi akad yaitu dapat merusak akad. Inilah hakikat dari riba. Semula akad jual beli itu sah, akan tetapi karena tercampuri oleh riba, maka akad jual beli tersebut jadi rusak. Syamsudin Al-zahabi dalam Kitab al-Kabar memasukkan riba sebagai bagian dari tujuh puluh macam dosa besar. Rasulullah dalam sebuah hadisnya pernah menulis surat kepada Majusi Hajar yang senang mempraktikkan riba, yang isinya berbunyi: "Apakah kalian akan meninggalkan perbuatan riba atau mengizinkan Allah dan Rasul-Nya memerangi kalian." Teks hadis tersebut bersandar pada Surah al-Baqarah ayat 279 yang menegaskan jika tidak meninggalkan riba, maka Allah dan RasulNya akan memeranginya, karena kerusakan yang diakibatkan karena riba lebih besar dibanding dengan kerusakan yang diakibatkan karena gharar.(E. Hidayat, 2019, p. 306). Namun bukan berarti jual beli yang terdapat unsur gharar dapat dikatakan sah. Para ulama sepakat bahwa jual beli yang terdapat unsur gharar tidak sah, karena pada jual beli yang terdapat unsur gharar masih terdapat ketidakjelasan dalam transaksi jual beli tersebut (Salim, 2017, p. 379).

\section{d. Kaidah keempat}

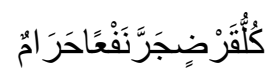

Artinya:

Setiap hutang-piutang yang menarik manfaat adalah diharamkan.

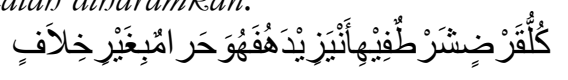

Artinya:

Setiap butang-piutang yang disyaratkan di dalamnya ada tambaban, maka hal itu dibaramkan tanpa adanya perbedaan.

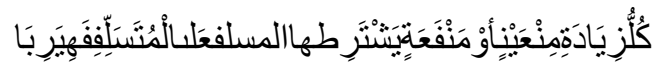

Artinya:

Setiap tambahan benda atau manfaat yang disyaratkan oleh pemberi pinjaman kepada peminjam adalab riba.

Kaidah tersebut maksudnya berkaitan dengan utang-piutang yang di dalamnya terdapat tambahan yang disyaratkan oleh pemberi pinjaman kepada peminjam, meskipun disetujui oleh 
peminjam, maka hal tersebut tergolong ke dalam riba. Hal ini sebagaimana firman Allah s.w.t. dalam surat al-Baqarah ayat 278:

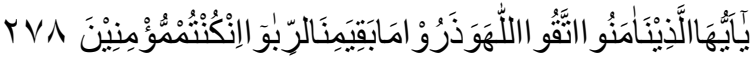

Artinya:

Wahai orang-orang yang beriman! Bertakwalah kepada Allah dan tinggalkan sisa riba (yang belum dipungut) jika kamu orang beriman(Departemen Agama RI, 2010).

Ayat di atas menjelaskan apabila salah satu pihak dalam transaksi utang-piutang mengambil tambahan dari pinjaman maka termasuk kategori(T. Hidayat, Tanti, \& Permata, 2019, p. 91). Hal ini berbeda jika tidak disyaratkan sebelumnya oleh pemberi pinjaman, melainkan hanya keridhaan pihak peminjam karena jasa yang telah diberikan pemberi pinjaman. Maka, hal tersebut tidak tergolong riba. Tidak ada pertentangan di antara para ulama mengenai masalah tersebut. Dengan demikian, dapat dikatakan telah terjadi ijma' di kalangan para ulama. Terlepas apakah tambahan tersebut beruap benda, seperti uang dan lain sebagainya; atau manfaat, seperti tenaga dalam melakukan sebuah pekerjaan, dan lain sebagainya. Contoh kasus tambahan berupa benda: Ahmad meminjamkan uang kepada Ruslan sebesar Rp. 100.000,- dengan mensyaratkan agar Ruslan harus mengembalikannya sebesar Rp. 120.000,-. Hal ini berbeda jika Ruslan mengembalikan seharga demikian yang sebelumnya tanpa disyaratkan oleh Ahmad. Contoh kasus tambahan berupa manfaat: Sofyan meminjamkan uang kepada Rusli sebesar Rp. 100.000,dengan syarat Rusli harus mengantarkannya ke Bandara pada hari tertentu, tanpa harus diberi imbalan; atau dengan syarat Rusli harus bekerja di perusahaan milik Sofyan, tanpa harus diberi gaji. Dalam kasus terakhir jelas sekali terjadi tambahan berupa manfaat yang dalam hal ini tenaga Rusli untuk kepentingan Sofyan (E. Hidayat, 2019, p. 307).

\section{e. Kaidah kelima}

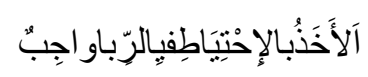

Artinya:

Berpegang teguh kepada kehati-hatian dalam masalah riba adalah wajib.

Kaidah tersebut maksudnya berkaitan dengan larangan riba dibangun atas dasar kehatihatian dalam agama. Oleh karena itu, wajar kerusakan yang diakibatkan karena riba lebih besar dibanding karena gharar, dan riba sendiri dapat merusak akad sebagaimana telah dikemukakan dalam kaidah sebelumnya. Hal ini tentunya berbeda dengan kehati-hatian dalam menghindarkan perkara syubhat, karena tidak jelas hala dan haramnya. Namun menghindarkannya lebih baik guna memelihara kebersihan agama. Adapun kehati-hatian dalam menghindarkan riba hukumnya 
wajib, karena hukumnya sudah jelas haram berdasarkan Al-Quran, hadis dan ijma', dan telah menjadi urusan agama yang diketahui secara pasti (ma ulima minaddin biddarurat)(E. Hidayat, 2019, p. 308). Motivasi utama seorang Muslim untuk mencari nafkah adalah mendapatkan harta yang halal. Berkerja dengan maksud mendapatkan harta yang halal dapat dikategorikan ibadah. Maka dalam ini seorang Muslim harus melakukan dengan prinsip kehati-hatian sehingga terlepas dari perbuatan dan hal yangdilarang oleh Islam(Ully \& Kelib, 2012, p. 145). Contoh dari aplikasi kaidah tersebut adalah semisal menghindarkan terjadinya tukar-menukar benda ribawi, seperti emas, perak, kurma, gandum, atau yang lainnya, tanpa ditakar atau ditimbang (E. Hidayat, 2019, p. 308).

\section{f. Kaidah keenam}

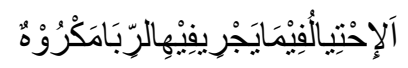

Artinya:

Siasat terbadap sesuatu agar di dalamnya berjalan riba adalah dibenci.

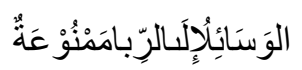

Artinya:

Perantara yang dapat menghantarkan kepada riba adalab dilarang.

Kaidah tersebut maksudnya berkaitan degan siasat atau upaya apa saja atau perantara agar riba berjalan dalam muamalah adalah dibenci dan dilarang. Hal tersebut bisa bermakna dukungan, kerja sama, perjanjian, makelar, atau peraturan yang dikeluarkan oleh pemerintah. Dengan demikian, siapa saja yang terlibat agar riba berjalan dengan baik, maka hukumnya berdosa. Tidak hanya pelaku saja yang berdosa, melainkan saksi, pengantar, pencatatnya, dan yang lainnya juga semuanya ikut berdosa. Oleh karena itu, perbuatan riba ini dampaknya tidak hanya dirasakan oleh individu, juga oleh masyarakat luas, dan pintu keberkahan akan dihapus dengan perbuatan riba tersebut (E. Hidayat, 2019, p. 309).Rasulullah s.a.w. mengecam orangorang yang terlibat dalamtransaksi riba, baik melalui utang-piutang, jual beliyang bermaksud agar hartanya bisabertambah, orang yang mewakili dalamtransaksi riba, menulis atau menjadisaksinya. Riba dimasukkan sebagai salahsatu dari tujuh dosa besar yang harusdijauhi oleh seorang muslim(Setyawati, 2017, p. 268).

\section{g. Kaidah ketujuh}

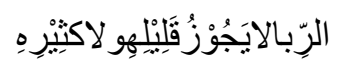

Artinya:

Riba tidak diperbolebkan, baik sedikit maupun besar. 
Doli Witro dkk. Qaidah Furu’ Fi Al-Riba dan Implementasinya

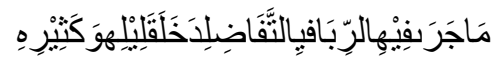

Artinya:

Riba yang berjalan di dalamnya karena adanya kelebihan, maka termasuk juga sedikit dan besarnya.

Kaidah tersebut maksudnya berkaitan dengan hukum haramnya riba itu terlepas apakah sedikit atau banyak. Artinya, tetap saja haram. Meskipun ada ayat yang menjelaskan larangan memakan riba yang berlipat ganda (Surah ali Imran:130), namun maksudnya ayat tersebut menggambarkan praktik riba berlipat ganda yang dijalankan oleh orang Yahudi dan bangsa Arab Jahiliah, sehingga apabila pada waktunya peminjam tidak bisa membayarnya, maka pemberi pinjaman berkata: “Apakah engkau mau membayar utang atau bertambah bungannya." Akhirnya peminjam terpaksa harus menerima berlipat riba karena kebutuhan yang mendesak. Dalam AlQuran Surah al-Nisa' ayat 161, Allah s.w.t. berfirman:

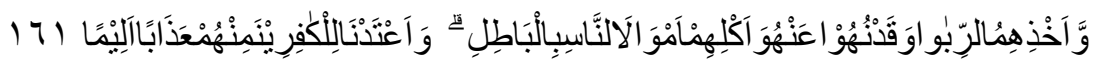

Artinya:

Dan karena mereka menjalankan riba, padahal sunggub mereka telah dilarang darinya, dan karena mereka memakan harta orang dengan cara tidak sah (batil). Dan Kami sediakan untuk orang-orang kafir di antara mereka azab yang pedih(Departemen Agama RI, 2010).

Ayat di atas menjelaskan bahwa Allah memberi siksaan yang pedih karena orang Yahudi memakan riba serta memakan harta dengan jalan batil seperti suap-menyuap dan menipu. Larangan tersebut tidak berarti menunjukkan lebih baik mempraktikkan riba yang berlipat ganda daripada yang sedikit, karena dosanya sama juga. Larangan tersebut bersifat umum agar kita menjauhinya, terlepas sedikit atau berlipat ganda, karena baik yang sedikit apalagi yang berlipat ganda dapat merusak akad. Termasuk juga sebagaimana dijelaskan kaidah selanjutnya jika seseorang tukar-menukar benda ribawi yang di dalamnya ada kelebihan atau tidak sama jumlah kadarnya. Dalam hal ini terlepas apakah kelebihan itu sedikit atau banyak. Sementara tetap haram (E. Hidayat, 2019, pp. 209-310).

\section{h. Kaidah kedelapan}

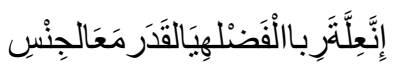

Artinya:

Sesunggubnya ilat riba Fadhal adalah ukuran dan jenis.

Kaidah tersebut maksudnya berkaitan dengan sesuatu itu disebut dengan riba fadhal karena ukuran dan jenisnya. Ukuran di sini seperti ditakar atau ditimbang. Sedangkan jenis di sini 
seperti jenis barang itu termasuk benda ribawi, seperti emas, perak, gandum, jemawut, kurma, dan garam sebagaimana dijelaskan dalam Hadis Nabi riwayat Muslim dari Abu Said al-Khudri ditambah dengan mata uang negara tertentu dan makanan pokok serta makanan tambahan masing-masing daerah sebagaimana telah disebutkan di atas. Maka, jika barang itu termasuk benda ribawi, maka kualitasnya harus sama, kontan (bulul), dam serah terima (taqabud). Oleh karena itu, jika tidak memenuhi syarat tersebut, maka tergolong ke dalam riba fadhal (E. Hidayat, 2019, pp. 310-311).Riba fadhalyaitu menjual (menukar) uang dengan uang, atau makanan dengan makanan dengan ada penambahan(Sulaemang L, 2015, p. 167). Riba jenis ini seringterjadi ketika satu pihak melebihkan keuntungan (harta) dari satu pihak terhadap pihak lain dalam suatu transaksi jual beli atau pertukaran barang sejenis dengan tanpa memberikan imbalan terhadap kelebihan tersebut(Ramly, 2017, p. 185).

\section{i. Kaidah kesembilan}

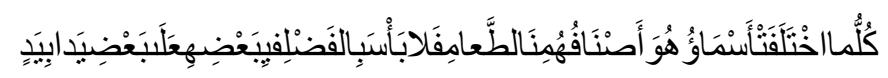

Artinya:

Setiap sesuatu yang berbeda namanya, jenisnya dari makanan pokok, maka diperbolebkan adanya kelebihan sebagiannya dengan syarat kontan.

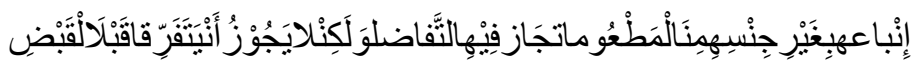

Artinya:

Jika seseorang menukarkan makanan yang berbeda jenisnya, maka diperbolebkan adanya kelebihan. Tetapi tidak diperbolehkan adanya kelebihan. Tetapi tidak. diperbolebkean adanya berpisah sebelum serab terima.

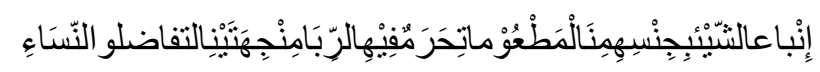

Artinya:

Jika seseorang menukar sesuatu yang sejenis dari makanan, makanan dibaramkan adanya riba dari dua arah, yakni adanya kelebihan dan penyerahannya ditanggubkan.

Kaidah tersebut maksudnya berkaitan dengan syarat yang harus terpenuhi agar terhindar dari riba. Kaidah pertama dan kedua ini berkaitan dengan syarat adanya kontan (yadan bi yadin) atau penyerahan barang ketika akad (taqabud). Jika yang ditukarkan itu benda ribawi yang beda jenisnya dan termasuk makanan pokok, seperti beras, gandum, dan jagung; atau makanan tambahan atau pelengkap seperti sayuran-sayuran dan buah-buahan. Misalnya, seseorang menukarkan beras sebanyak $1 \mathrm{Kg}$ dengan gandum sebanyak $1.5 \mathrm{Kg}$; atau menukarkan 2 bejana sayuran wortel dengan 1 bejana buah mangga. Sedangkan penjelasan kaidah ketiga adalah sebaliknya. Jika yang ditukarkan itu sejenis, maka syaratnya ada dua, yakni: 1) sama jumlah dan 
Doli Witro dkk. Qaidah Furu' Fi Al-Riba dan Implementasinya

kadarnya (tamasul); dan 2) barangnya diserahkan ketika akad (taqabud) (E. Hidayat, 2019, pp. 311312).

\section{j. Kaidah kesepuluh}

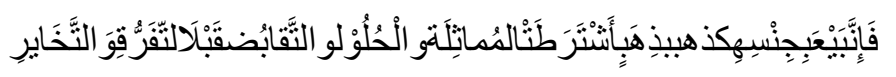

Artinya:

Jika yang dipertukarkan itu sejenis seperti emas dengan emas, maka disyaratkan adanya persamaan, kontan, serah terima sebelum berpisah dan mengadakan khiyar.

Kaidah tersebut maksudnya berkaitan dengan tukar-menukar benda ribawi yang sejenis, seperti emas dengan emas lagi disyaratkan harus jumlah dan kadarnya sama (tamasul), kontan (bulul), dan diserahkan ketika akad (taqabud). Hal ini untuk menghindari terjadinya riba fadhal. Misalnya, seseorang menukarkan emas sebanyak 80 gram dengan emas dalam bentuk lainnya sebanyak 80 gram. Untuk konteks zaman sekarang, menukar mata uang rupiah dengan rupiah lagi, seperti seseorang menukarkan uang sebesar Rp. 10.000,- dengan Rp. 10.000,- yang berbentuk Rp. 5.000 sebanyak dua lembar. Hal ini berbeda jika seseorang menukarkan uang sebesar Rp. 14.000,- dengan 1 dolar Amerika; atau dengan mata uang lainnya. Dengan kata lain, jika berbeda jenis, jumlah, dan kadarnya, maka hal ini diperbolehkan asalkan syaratnya, diserahkan ketika akad (taqabud). Oleh karena itu, jika tidak demikian, maka tergolong ke dalam riba fadhal (E. Hidayat, 2019, p. 312).

\section{SIMPULAN}

Dalam Islam, transaksi muamalah dalam bentuk apapun tidak dilarang, namun transaksi muamalah yang dilarang adalah transaksi muamalah yang mengandung unsur riba. Setiap muslim dianjurkan tidak mendekati praktik muamalah yang syubhat karena akan berpotensi akan terjerumus kepada riba. Allah dan Rasul mengharamkan riba karena dapat memberikan mudarat kepada manusia. Salah satu dampak yang jelas yang diterima adalah salah satu pihak membayar/mengganti lebih banyak dari yang dipinjam sebelumnya. Dengan adanya kaidahkaidah fikih yang telah ditetapkan oleh ulama yang digali dari Al-Quran dan hadis dapat membantu manusia dalam memahami nash yang terdapat dalam hukum Islam khususnya tentang riba.

\section{REFERENSI}

Bakar, A. (2018). RIBA DALAM MUAMALAH (Studi Terhadap Hadis-Hadis Riba). Skripsi, 1- 
150.

Batubara, D. (2017). Solusi Ekonomi Islam Terhadap Rekayasa Helah (Praktek Riba). ALFALAH : Journal of Islamic Economics, 2(2), 123-138. https://doi.org/10.29240/jie.v2i2.262 Busyro. (2009). RIBA DALAM AL-QUR'AN DAN SUNNAH (Kajian tematik Ayat-ayat dan Hadis Ahkam). Al-Hurriyah, 10(1), 1-17. https://doi.org/10.30983/alhurriyah.v10i1.372

Chair, W. (2014). Riba Dalam Perspektif Islam Dan Sejarah. IQTISHADIA: Jurnal Ekonomi \& Perbankan Syariah, 1(1), 98-113. https://doi.org/10.19105/iqtishadia.v1i1.368

Dakhoir, A., \& Tarantang, J. (2020). HUKUM BUNGA BANK (Pendekatan Fikih Wasathiyah Iqtishadiyah) (I. E. A. S. Pelu, ed.). Yogyakarta: Penerbit K-Media.

Departemen Agama RI. (2010). Al-Quran dan Terjemahnya. Bandung: Syaamil Qur'an.

Fahriana, L., \& Muslimin, J. (2020). Penerapan al-Qawācid al-Uș uliyyah dan al-Qawācid alFiqhiyah dalam Kasus Riba dan Bank Syari’ah. Jurnal Indo-Islamika, 10(2), 92-106. https://doi.org/10.15408/idi.v10i2.17527

Hammam. (2017). Urgensi Kaidah Fiqhiyyah Dalam Perumusan Hukum dan Implemetasinya Dalam Fatwa DSN-MUI. Et-Tijarie, 4(1), 49-75. Retrieved from https://journal.trunojoyo.ac.id/ettijarie/article/view/3900

Hidayat, E. (2019). Kaidah Fikih Mualamah. Bandung: PT Remaja Rosdakarya.

Hidayat, T., Tanti, T., \& Permata, C. (2019). HUKUM PENGAMBILAN MANFAAT QARDH TERHADAP PRAKTEK ARISAN UANG PERSPEKTIF IBNU QUDAMAH (Studi Kasus di Desa Gunting Saga Kecamatan Kualuh Selatan Kabupaten Labuhan Batu Utara). Islamic Business Law Review, 1(1), 80-95. Retrieved from http://jurnal.uinsu.ac.id/index.php/iblr/article/view/6516

Irawati, I., \& Akramunnas, A. (2018). Pengetahuan Masyarakat Tentang Riba Terhadap Perilaku Utang Piutang Di Kecamatan Anreapi Polewali Mandar. Laa Maisyir: Jurnal Ekonomi Islam, 5(2), 109-122. https://doi.org/10.24252/lamaisyir.v5i2.7275

Marwini. (2017). Kontroversi Riba Dalam Perbankan Konvensional Dan Dampaknya Terhadap Perekonomian. Az Zarqa', 9(1), 1-18.

Miles, M. B., \& Huberman, A. M. (1984). Qualitative Data Analysis (a Source book of New Methods). Beverly Hills: Sage Publications.

Nurhadi, N. (2019). Tematik Hadis Tentang Riba Dalam Kitab Shahih Bukhari. Syarikat: Jurnal Rumpun Ekonomi Syariah, 2(1), 75-90. https://doi.org/10.25299/syarikat.2019.vol2(1).3726

Qadir, D. A. (2014). Anatomi Keabsahan Bunga Bank Dalam Perspektif Teori Limit Muhammad Syahrûr. Asy-Syari'ah, 16(1), 77-88. https://doi.org/10.15575/as.v16i1.628

Ramly, A. R. (2017). Analisis Jual Beli Modern dalam Islam. Jurnal Akad, 1(1), 184-202. 
Doli Witro dkk. Qaidah Furu' Fi Al-Riba dan Implementasinya

Retrieved from http://ojs.serambimekkah.ac.id/akad/article/view/240

Salam, A. (2016). Bunga Bank Dalam Perspektif Islam (Studi Pendapat Nahdlatul Ulama Dan Muhammadiyah). JESI (Jurnal Ekonomi Syariah Indonesia), 3(1), 77-108. https://doi.org/10.21927/jesi.2013.3(1).77-108

Salim, M. (2017). Jual Beli Secara Online Menurut Pandangan Hukum Islam. Al Daulab : Jurnal Hukum Pidana Dan Ketatanegaraan, 6(2), 371-386. https://doi.org/10.24252/ad.v6i2.4890

Setyawati, F. (2017). Riba dalam Pandangan Al-Qur'an dan Hadis. Al-Intaj : Jurnal Ekonomi Dan Perbankan Syariah, 3(2), 257-271. https://doi.org/10.29300/aij.v3i2.2210

Sulaemang L. (2015). Hukum Riba dalam Perspektif Hadis Jabir ra. Jurnal Al-'Adl, 8(1), 156-172. https://doi.org/10.31332/aladl.v8i1.355

Ully, A., \& Kelib, A. (2012). Penerapan Prinsip-Prinsip Islam Dalam Pengaturan Corporate Social Responsibility Di Indonesia. Law Reform, 7(2), 121-189. https://doi.org/10.14710/lr.v7i2.12413

Wijaya, M. (2007). PEMAHAMAN MASYARAKAT TENTANG RIBA DALAMKEGIATAN PEREKONOMIAN(Studi Kasus di Desa Dinoyo Kecamatan Jatirejo Kabupaten Mojokerto). Skripsi. Retrieved from http://eprints.umm.ac.id/8312/

Witro, D. (2019). Praktek Jual Beli Parang dengan Cara Penumpukan untuk Meningkatkan Harga di Desa Koto Padang Perspektif Hukum Islam. Al-Qisthu: Jurnal Kajian Ilmu-Imu Hukum, 17(1), 34-40. https://doi.org/10.32694/010710

Witro, D. (2021). Qaidah furu' fi al-hiwalah: Sebuah tinjauan umum. Qawãnïn: Journal of Economic Syaria Law, 5(1), 1-12. https://doi.org/10.30762/qawanin.v5i1.2897 